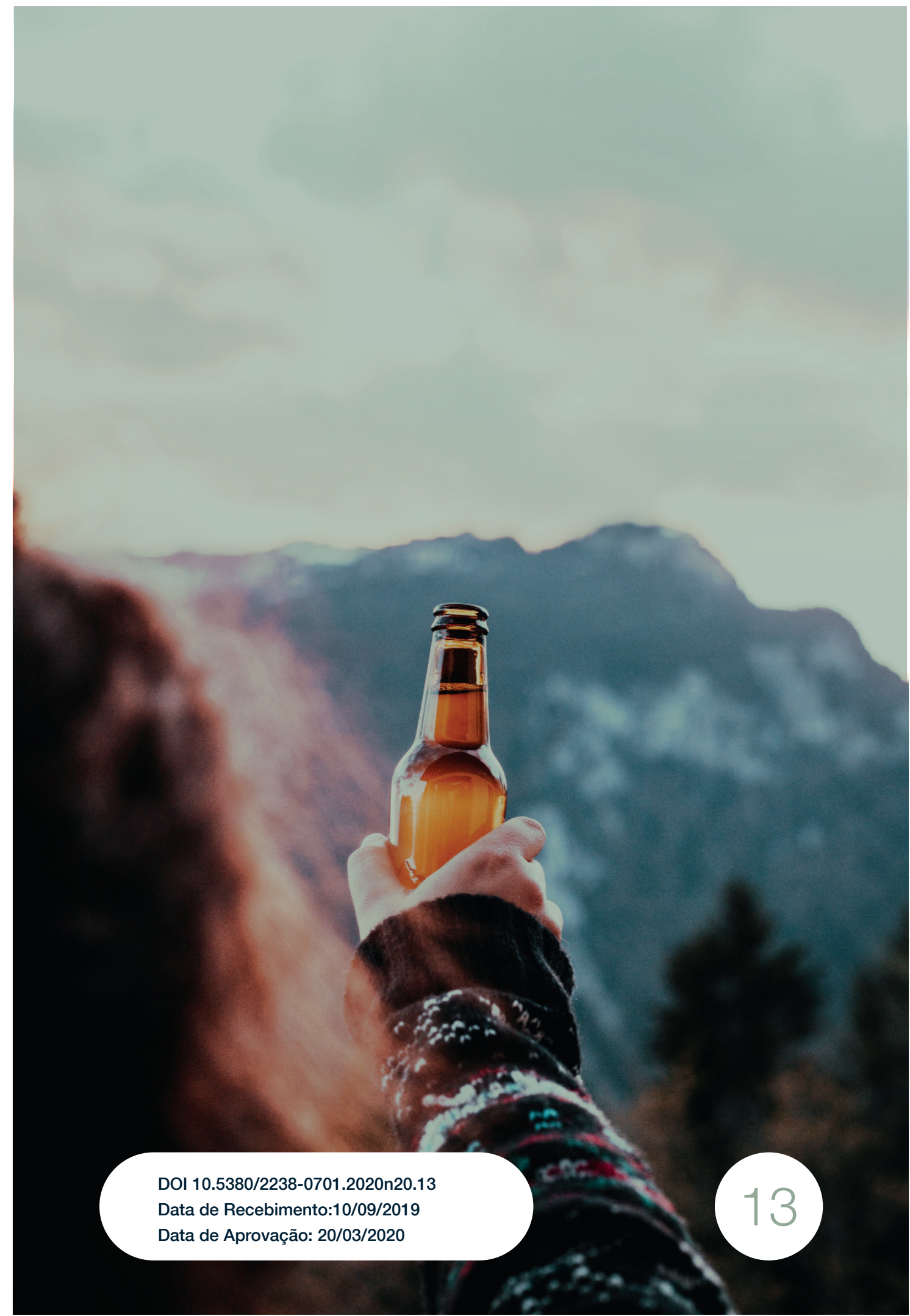


O uso dos arquétipos na imagem e identidade das marcas: um estudo da marca Skol 


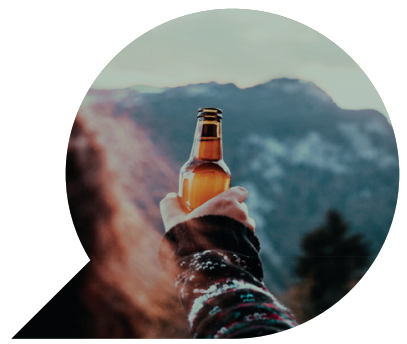

\section{O uso dos arquétipos na imagem e identidade das marcas: um estudo da marca Skol}

The use of archetypes in brand image and identity: a Skol brand study

El uso de arquetipos en la imagen y la identidad de la marca: un estudio de la marca Skol

\begin{tabular}{|c|}
\hline MANOELLA FORTES FIEBIG ${ }^{1}$ \\
\hline CIRO GUSATTI ${ }^{2}$ \\
\hline DOUGLAS HAUENSTEIN PETRY ${ }^{3}$ \\
\hline
\end{tabular}

Resumo: O estudo tem como objetivo descobrir quais arquétipos são percebidos na marca Skol pelo público consumidor em duas fases de sua comunicação: em uma campanha antiga (de 2010) e em uma campanha mais recente (de 2017). Com o auxílio de um método experimental de pesquisa, os dados foram coletados e analisados pelos testes ANOVA e Tukey, a fim de observar as dife-

1 Doutoranda em Comunicação pela Universidade Federal do Paraná. Mestre em Comunicação pelo Programa de Pós Graduação em Comunicação da Universidade Federal do Paraná (UFPR). Jornalista pela Universidade Federal de Santa Maria (UFSM). Bolsista CAPES e pesquisadora do Grupo COMXXI. 2 Mestre em Administração pela Universidade de Santa Cruz do Sul (UNISC). Especialista em Marketing de Serviços na Escola Superior de Propaganda e Marketing (ESPM). Publicitário (UPF). Graduado em Administração na Unisinos. Professor do curso de Publicidade e Propaganda na Universidade de Passo Fundo.

3 Publicitário (Universidade de Passo Fundo). 
renças estatísticas das respostas obtidas. Variações significativas foram encontradas na análise, pois enquanto os arquétipos do Mago e do Amante eram percebidos com mais força na imagem antiga da marca, na imagem atual há um aumento da percepção dos arquétipos do Explorador e do Prestativo. Entretanto, o arquétipo mais percebido pelos consumidores em todos os casos foi o do Bobo da Corte.

Palavras-chave: Arquétipos de marca. Imagem e identidade. Marcas. Publicidade.

\begin{abstract}
The study aims to find out which archetypes are perceived in the Skol brand by the consumer public in two phases of their communication: in an old campaign (2010) and in a current campaign (2017). Through an experimental research method, data were collected and analyzed by ANOVA and Tukey tests, in order to present the statistical differences in the results obtained. Significant variations were found in the analysis, because while the Wizard and Lover archetypes were perceived more strongly in the old brand image, in the current image there is an increased perception of the Explorer and the Servant archetypes. However, the archetype most perceived by consumers in all of the cases was the Court Jester.
\end{abstract}

Keywords: Brand Archetypes. Image and Identity. Brands. Advertising.

Resumen: El objetivo del estudio es averiguar qué arquetipos son percibidos en la marca Skol por el público consumidor en dos fases de su comunicación: una campaña antigua (2010) y una campaña actual (2017). Mediante un método de investigación experimental, los datos se recopilaron y se analizaron mediante ANOVA y Tukey, con el fin de presentar las diferencias estadísticas en los resultados. Se encontraron variaciones significativas en el análisis, ya que si bien los arquetipos de Mago y Amante se percibieron con mayor fuerza en la imagen de la marca anterior, en la imagen actual hay una mayor percepción del arquetipo del Explorador y del Servidor. Sin embargo, el arquetipo más percibido por los con- 
sumidores en los casos fue el del Payaso.

Palabras clave: Arquetipos de marca. Imagen e identidad. Marcas.

Publicidad.

\section{Introdução}

Na busca pela construção de uma relação simbólica com os consumidores, diversas marcas criam associações com figuras arquetípicas para fortalecer seu posicionamento, bem como criar proximidade e identificação com seu público. Este artigo, que se propõe a apresentar uma revisão bibliográfica sobre marca e sua relação com a identidade das empresas, realiza, por meio de uma metodologia comparativa e uma abordagem quantitativa sobre os dados de coleta, uma reflexão sobre o posicionamento da marca de cerveja Skol sob orientação da teoria dos arquétipos. O artigo figura como um recorte da pesquisa de conclusão de curso em Publicidade e Propaganda de um dos autores, sob orientação dos demais. Para tanto, opta-se por demonstrar os dados obtidos por meio de uma análise de variância das médias do corpus, cuja função principal é detectar a diferença da recepção (público) acerca da imagem da marca em dois momentos distintos da sua história. Desta forma, refletimos sobre o conceito nuclear de marca, suas contribuições ao campo da Publicidade e Propaganda e, por fim, apresentamos a teoria dos arquétipos, para, então, discutir os resultados e procedimentos aplicados para a análise, bem como a metodologia empregada.

\section{Marca, imagem e identidade}

O objetivo básico de uma marca é, impreterivelmente, se diferenciar das demais, agregar valor a uma empresa ou produto, ser o seu diferencial, ou simplesmente demarcar o perfil de uma organização. Na antiguidade, os comerciantes tinham o costume de indicar a proveniência do produto agrícola ou manufaturado que era oferecido aos consumidores, tendo a "marca" - diferente do significado atual - como referência da qualidade do produto e de seu prestígio (PINHO, 1996). Um exemplo 
disso é a marca Champanhe, que leva esse nome pelo local de sua produção, a região de Champagne, na França. Ainda, à época, a sua principal função era diferenciar os produtos e isso se comprova quando recorremos à sua etimologia: na língua inglesa a palavra "marca" é chamada de brand, que deriva do norueguês brandr que significa queimar como o gado que é marcado pelo seu proprietário para diferenciá-lo dos demais - desta forma, o termo "marca" está ligado diretamente à sua origem de diferenciação de produtos de diferentes proprietários (SCHULTZ; BARNES, 2001). Hoje, o termo não se aplica apenas aos produtos, mas também serve para diferenciar empresas, companhias, organizações e grandes corporações globalizadas. Para Aaker (1998), uma marca pode ser definida, em primeira instância, como apenas um nome diferenciado, ou, ainda, como um símbolo visual (um logotipo, uma marca registrada, ou um até mesmo um desenho). O objetivo deste nome ou símbolo seria o de se diferenciar das demais empresas concorrentes, ou seja, seria uma forma de criar identificação. Sendo assim, "uma marca sinaliza ao consumidor a origem do produto e protege, tanto o consumidor quanto o fabricante, dos concorrentes que oferecem produtos que pareçam idênticos" (AAKER, 1998, p. 7). De qualquer forma, criar uma identidade para as marcas, no entanto, vai muito além da simples diferenciação em relação à concorrência mercadológica. Como veremos a seguir, vários pesquisadores se empenharam em realizar pesquisas atrelando a criação de marcas a outros aspectos importantes para as empresas, estendendo a discussão para temas como a aproximação da marca com o público, a fidelização da marca frente aos seus consumidores, a divulgação de valores e militâncias da empresa em busca de um posicionamento definido, a identificação de seus produtos, e, até, a criação de vínculos emocionais com os consumidores ou público da marca.

O INPI - Instituto Nacional de Propriedade Industrial - afirma que marca "é todo sinal distintivo, visualmente perceptível, que identifica e distingue produtos e serviços" (INPI, 2016, online). Esta passagem, retirada do site da organização, refere-se principalmente à representação visual das marcas, como o seu logotipo, por exemplo. Entretanto, o conceito de marca significa muito além de seus elementos de design. Atualmente o termo "marca" transcende a ideia de diferenciação entre as demais empresas do mesmo segmento, pois as marcas possuem (e buscam por) uma representação idealizada, um significante na mente 
dos consumidores e um posicionamento memorável e efetivo. De modo geral, Aaker (2007) explicita que pode-se definir uma marca como um signo, conforme a semiologia, já que toda marca é dotada de um significante - aquilo que ela deseja representar - e de um significado - como ela é vista, o que ela representa de fato. Portanto, além das marcas buscarem a diferenciação entre produtos concorrentes, elas também têm o objetivo de adquirir um significado na cabeça do consumidor, podendo gerar associações positivas que ampliam e reforçam o valor de um produto. Tomiya (2010) explica que as marcas fazem parte do dia a dia dos consumidores e seus atributos influenciam, inclusive, no processo de decisão de compra dos indivíduos, sendo a marca um facilitador nesse processo de decisão, conforme as associações do consumidor com as qualidades e atributos percebidos em relação à marca.

Lindstrom (2012) afirma que marca é uma síntese de experiências ou associações e, por conseguinte, deve estabelecer uma conexão emocional e até sinestésica, possivelmente, com seus consumidores. Isto pode ser observado quando nos deparamos com marcas que fizeram parte da nossa infância, por exemplo, que remontam a um outro momento e possuem um significado especial para aquele consumidor nostálgico. Sendo assim, o vínculo afetivo e emocional com a marca se instaura no imaginário do consumidor. Já Solomon (2002) explora essa ideia afirmando que uma das características do mercado contemporâneo é a de que as pessoas possuem a propensão a comprar produtos não pelo que eles fazem, mas sim pelo que eles significam, criando-se uma relação emocional e subjetiva com o objeto e a marca. Desta forma, com base em todos estes pesquisadores (e outros que exploram o tema de maneira extensiva), pode-se inferir que, no final, as marcas têm algo em comum: buscam adquirir um significado emocional para criar uma conexão com seu público. Visando criar esse significado emocional na mente de seus consumidores e uma conexão com o público, as marcas trabalham o seu significante por meio da criação de uma identidade própria. Torquato (1991) defende que a identidade de uma marca é formada principalmente pelos seus valores, princípios e conceitos, figurando como a "personalidade" de uma organização. Outrossim, essa personalidade, segundo o autor, estaria intimamente relacionada com as percepções subjetivas construídas intencionalmente pela marca.

O conceito de identidade é definido por Khauaja (2008) como um 
conceito de emissão, ou seja, a forma como a empresa comunica seu posicionamento e é percebida pelo seu público. Aaker (1996) complementa dizendo que a identidade de uma marca pode ser considerada como um conjunto de associações. Essas associações, no entanto, seriam intencionais, já que caberia ao estrategista da marca (um publicitário, designer, relações públicas) criar ou manter associações entre a marca e os significados que desejam reproduzir para o mercado e para o público externo. Segundo o autor, "Essas associações representam aquilo que a marca pretende realizar e implicam uma promessa aos clientes, feita pelos membros da organização" (AAKER, 1996, p. 80).

Os conceitos de marca e identidade são essenciais para produzir o posicionamento de qualquer empresa na contemporaneidade, pois é a partir da relação entre ambas que se constrói a credibilidade de uma marca. É no resultado da comparação entre o que a marca diz ser e o que a marca realmente é que o consumidor cria as associações mentais daquilo que ele acredita sobre ela, podendo criar empatia ou não sobre a marca. Outra característica importante das marcas é o seu posicionamento, que vai além da simples criação de uma identidade visual. O trabalho de posicionamento de uma marca é um dos primeiros passos na construção da identidade, afinal, é a partir do posicionamento que se definem quais estratégias de comunicação serão utilizadas e, principalmente, qual a mensagem e o conteúdo que serão transmitidos ao público alvo da instituição. Essa é a ação que fará com que o público enxergue a marca como única, ou seja, que fará com que uma marca se diferencie por meio de seus atributos das demais empresas. E esse é o objetivo de qualquer empresa: obter uma imagem positiva, ser única em seu ramo e conquistar a atenção e a empatia do consumidor com a ajuda de seu posicionamento. Ainda, Kapferer (1997) caracteriza o posicionamento como o valor percebido pelos consumidores sobre a marca, através dos conjuntos de associações, qualidades e diferenças que distinguem a marca dos seus concorrentes. Para Aaker (2007, p. 76), o posicionamento é "a parcela da identidade e da proposta de valor da marca que deve ser ativamente comunicada ao público-alvo e que apresenta uma vantagem em relação às marcas concorrentes", exercício que, por consequência, levaria a marca a ganhar a preferência do público. 


\section{Arquétipos de marca}

Uma das estratégias mais utilizadas para criar marcas de impacto e que geram conexões simbólicas e emocionais com o público é o uso de arquétipos pré-estabelecidos na comunicação dessas empresas. Do grego antigo, arkhé, era o termo utilizado pelos filósofos pré-socráticos para definir a origem da natureza e de todas as coisas, como que de forma mitológica, pois era a origem de tudo. Depois, o termo seria abordado por filósofos como Platão e Cícero com outra perspectiva, não mais se tratando da origem material das coisas, mas se referindo à origem do homem e de suas ideias, de forma mais subjetiva (MACIEL, 2000, p. 16). Para o psiquiatra Jung (2000), os arquétipos estão diretamente relacionados ao conceito de inconsciente coletivo, ou seja, pensamentos e ações que são comuns/universais a todos os seres humanos em seu inconsciente. Ele concluiu isso após perceber similaridades mentais e psíquicas entre ele e vários de seus pacientes durante anos, fato que o fez afirmar que há uma parte do inconsciente que conecta toda a humanidade. Dessa forma, Jung (2000) deduziu que os arquétipos nascem da repetição constante de um fato ou experiência de geração em geração. Um exemplo prático disso é o arquétipo do herói (bom) e do bandido (mau), onde em qualquer lugar do mundo haverá a compreensão de suas diferenças e significados.

No campo da comunicação - mais especificamente na publicidade e propaganda e nas áreas do marketing - são largamente utilizados recursos arquetípicos considerados como universais no entendimento antropológico, psicológico e sociológico, conforme descrevem as autoras MARK; PEARSON (2001):

\footnotetext{
A psicologia arquetípica ajuda-nos a compreender o significado intrínseco das categorias de produtos e, consequentemente, ajuda os profissionais de marketing a criar identidades de marcas duradouras que estabelecem o domínio do mercado, evocam nos consumidores o significado e o fixam, e inspiram a lealdade do consumidor. (MARK; PEARSON, 2001, p. 26).
}

Dessa forma, o uso dos arquétipos na construção das marcas e no que tange às suas simbologias se tornou uma ferramenta fundamental no processo de criação dos símbolos e significados das marcas, pois a estratégia de associação dos arquétipos às suas identidades ou aos seus produtos possibilita ao consumidor relacioná-las com um significa- 
do já pré existente, com histórias que aproximam a marca do sujeito, ou, simplesmente, com algo que remete ao inconsciente coletivo ou individual dos consumidores ou do público. Sendo assim, a construção de uma marca que se utiliza de ferramentas arquetípicas ganha uma personalidade e características que são, inclusive, similares ao seu próprio público alvo, tomando uma outra forma implícita na mente do consumidor (MARK; PEARSON, 2001). Aaker (1998) afirma que:

Todas as pessoas, naturalmente, possuem uma personalidade e um estilo de vida que é rico, complexo e também vivaz e distinto. Mas uma marca - mesmo uma máquina como um carro - pode ser impregnada de uma série de características muito similares de personalidade e de estilo de vida do consumidor, ou do seu proprietário (AAKER, 1998, p. 132).

Assim, os arquétipos na publicidade se debruçam sobre as necessidades e as motivações humanas, e se utilizam desse fator como uma espécie de estímulo na comercialização de produtos e/ou da própria imagem das marcas (isso porque há muitas marcas que procuram se vender antes mesmo de oferecer seus produtos aos consumidores).

Em suas pesquisas, os autores Mark e Pearson (2001) definiram um esquema estrutural indicando os quatro principais impulsos humanos, que correspondem aos conceitos de estabilidade, mestria, pertença e de independência. Considera-se, nesse artigo, que esses impulsos são relevantes para entender a relação entre a utilização dos arquétipos e os impulsos intrínsecos ao senso coletivo e, também, ao senso individual do sujeito. Conforme representada abaixo: 
Figura 01: As motivações humanas.

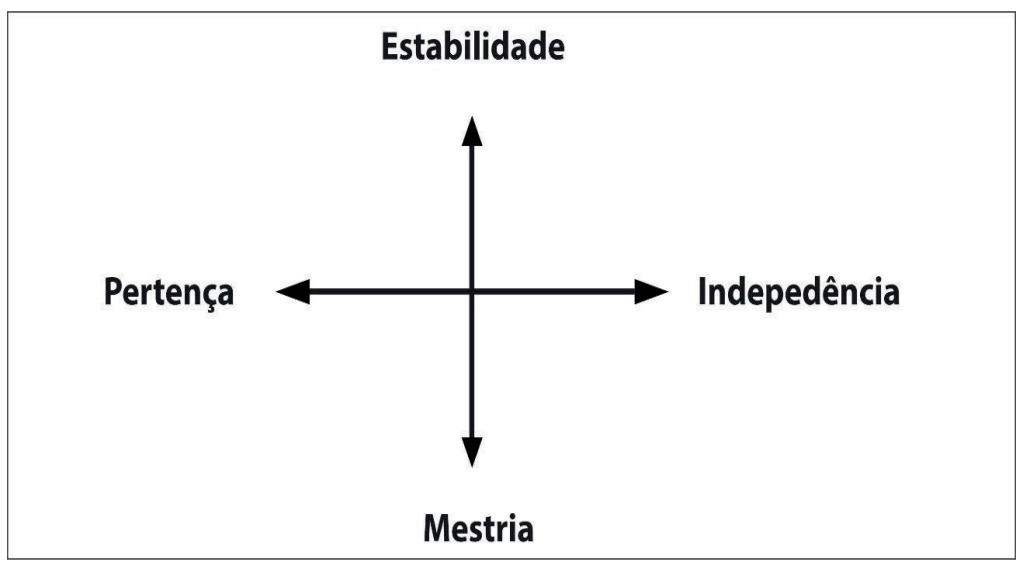

Fonte: MARK; PEARSON (2001, p. 28).

Os eixos opostos representam a busca pelo equilíbrio entre estabilidade e mestria e pertença e independência. Isso significa que "a maioria de nós quer muito ser apreciada e pertencer a um grupo. Ao mesmo tempo, também queremos ser individualizados e seguir nosso próprio caminho" (MARK; PEARSON, 2001, p. 28). Ambos os desejos são naturais do ser humano, porém seguem direções opostas, o que leva os indivíduos à procura pelo equilíbrio entre os dois eixos. Da mesma forma que as pessoas, os arquétipos também são motivados pelos impulsos, cada um com suas próprias características e virtudes. Assim, as autoras definiram doze padrões arquetípicos adaptados para o mundo da publicidade e que correspondem a esses impulsos (sejam eles combinados ou não), são eles:

\section{O Inocente:}

O arquétipo do inocente tem como principal característica a busca utópica de uma vida perfeita, que ela seja simples, leve e tranquila, onde as pessoas possam ser livres e felizes. Ele acredita na pureza e na bondade. Esse arquétipo é encontrado em muitas marcas de produtos naturais e orgânicos, pois a experiência do consumidor com esses produtos 
se dá de forma simples, natural e descomplicada, tal qual o arquétipo do inocente (MARK; PEARSON, 2001).

\section{O Explorador:}

O explorador é motivado pelo desejo de encontrar no mundo exterior um mundo melhor para si, ou seja, ele é movido por forças intrínsecas e extrínsecas. Almeja a liberdade e costuma ser crítico ao sistema, não se acomodando às coisas como elas são e indo atrás daquilo que acredita. Também possui características individualistas, é inquieto e insatisfeito (MARK; PEARSON, 2001).

\section{O Sábio:}

O sábio tem como objetivo buscar a verdade através do conhecimento e acredita que o aprendizado fará do mundo um lugar melhor. Esse arquétipo também almeja a liberdade e busca isso através da ciência e da inteligência. Está diretamente relacionado à professores, pesquisadores, eruditos e cientistas (MARK; PEARSON, 2001).

\section{O Herói:}

O principal objetivo desse arquétipo é superar grandes desafios, as adversidades e triunfar sobre o mal. É ambicioso e não tem medo de assumir os riscos, sempre está em busca de novos desafios e de se superar. Enquanto os arquétipos anteriores eram motivados pelo desejo de independência, o herói é motivado pela mestria (MARK; PEARSON, 2001).

\section{O Fora-da-lei:}

Também conhecido como rebelde, revolucionário, vilão ou inimigo, o fora-da-lei busca destruir os padrões impostos pela sociedade, quebrar 
as regras, causar mudanças e rupturas (MARK; PEARSON, 2001).

\section{O Mago:}

O arquétipo do mago tem como objetivo conhecer as leis fundamentais do funcionamento do universo e usar desse conhecimento como guia para a solução dos problemas. Ele é um agente da mudança, incentivando principalmente a mudança interior. Também é conhecido como visionário, catalisador, mediador, xamã ou curandeiro. (MARK; PEARSON, 2001).

\section{O Cara Comum:}

As principais virtudes deste arquétipo são a simplicidade e a necessidade de pertença, pois costuma se adequar para entrar ou pertencer a grupos sociais. É humilde e não deseja despertar a atenção nem possuir modos elitizados, é normalmente despojado e odeia artificialismos (MARK; PEARSON, 2001).

\section{O Amante:}

Apreciador da estética e dos prazeres, o arquétipo do amante busca a pertença tentando impressionar e atrair aqueles que deseja, utilizando do apelo sensual na maioria das vezes. (MARK; PEARSON, 2001).

\section{O Bobo da Corte:}

O principal objetivo do bobo da corte é a diversão, dele mesmo e dos demais. Gosta de desfrutar da vida, viver o hoje e ser feliz. Costuma não levar as coisas a sério e quebra as regras em nome da diversão. Diferente do arquétipo do cara comum que se adapta ao grupo motivado pelo desejo da pertença, o bobo da corte busca a pertença sendo autêntico e espontâneo (MARK; PEARSON, 2001). 


\section{O Prestativo:}

Motivado pela generosidade, compaixão e o desejo de ajudar as pessoas, o prestativo é o arquétipo que representa a empatia. Dessa forma, ele vê e sente as coisas na percepção do outro, escuta suas vontades e zela por aqueles que precisam, muitas vezes abrindo mão de suas próprias vontades (MARK; PEARSON, 2001).

\section{O Criador:}

Também conhecido como artista, inovador e sonhador, o criador busca criar algo novo como forma de auto expressão. Totalmente ligado à arte, busca a satisfação de seu desejo de estabilidade através dela (MARK; PEARSON, 2001).

\section{O Governante}

O governante tem como principal característica o desejo de estar no comando e no controle das coisas. Sua motivação é conquistar e se manter no poder, o que garante sua estabilidade e segurança. Por conta disto, frequentemente assume papéis de liderança (MARK; PEARSON, 2001).

\section{Arquétipos na marca skol}

Tendo em vista todos os arquétipos apresentados acima, estipulamos como metodologia de pesquisa a aplicação de questionários para compreender a percepção da recepção sobre determinadas peças da marca Skol, a fim de entender o seu posicionamento. Foram coletadas 30 respostas para cada questionário, em um total de 90 participantes. Destes, há uma maioria de participantes do sexo feminino, sendo 56\% dos participantes, contra 44\% do sexo masculino. Quanto à idade, 24\% 
responderam ter de 25 a 31 anos, enquanto $76 \%$ responderam ter de 18 a 24 anos. Também foram realizadas perguntas referentes ao consumo de cerveja dos respondentes, as quais $92 \%$ afirmaram consumir cerveja - com alta, média ou baixa frequência - enquanto apenas $8 \%$ afirmaram não consumir o produto. Em relação ao consumo da cerveja Skol, 89\% dos entrevistados afirmaram já ter consumido alguma vez o produto, enquanto $11 \%$ afirmaram nunca ter consumido a cerveja da marca.

Quanto às questões relacionadas aos arquétipos especificamente, razão pela qual movimentamos esse estudo, foram elaboradas frases que definissem cada um dos doze arquétipos. Desta forma, os respondentes deveriam mensurar em uma escala de 1 a 7 no quanto concordavam ou discordavam daquela definição para a marca, sendo 7 o padrão de máxima concordância e 1 o de mínima. Em cima dessas respostas, foram calculadas as médias de cada arquétipo em cada tratamento. 0 gráfico a seguir apresenta as médias dos arquétipos na campanha antiga da Skol.

Figura 01: Média dos Arquétipos - campanha antiga (2010).

\section{Campanha Antiga}

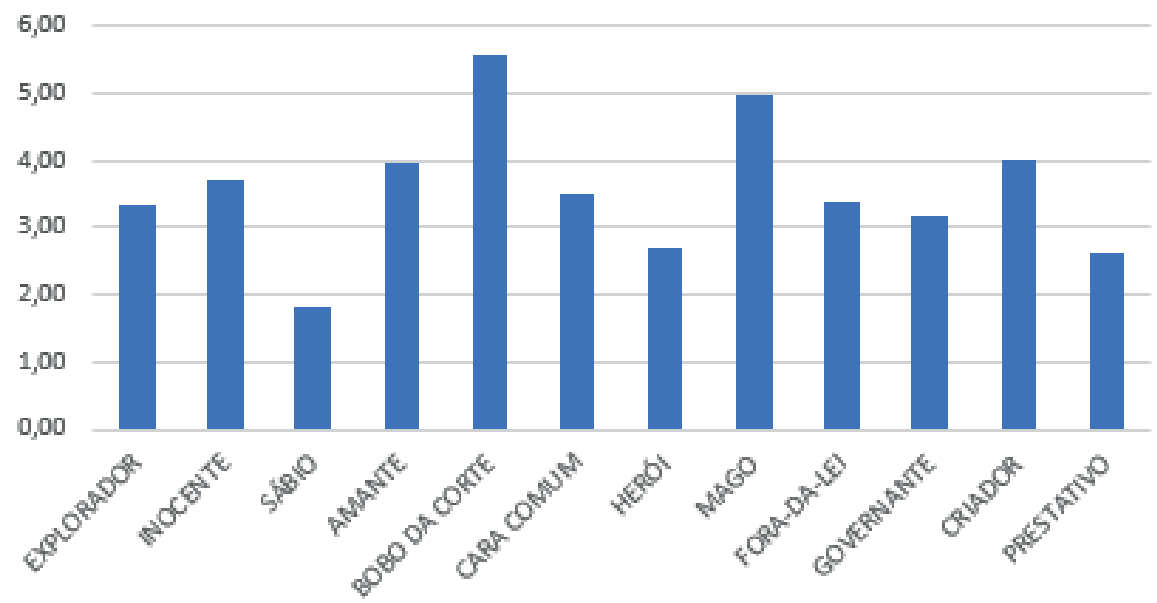

Fonte: elaborado pelos autores.

Percebe-se o destaque de dois arquétipos na comunicação antiga 
da Skol: o Bobo da Corte, qualificando a marca como divertida, descontraída e engraçada; e o Mago, que apresenta os produtos da marca como a solução para os problemas.

Ao analisar superficialmente o comercial apresentado na pesquisa como estímulo publicitário aos respondentes, percebe-se a evidência dos dois arquétipos. O comercial em questão trata-se de "Skol Litrão e Beto Barbosa", de 2010, no qual a Skol dá dicas cômicas de como "queimar o filme em um churrasco", apresentando claramente o lado Bobo da Corte da marca. O lado do Mago aparece quando o protagonista do comercial surge com a Skol Litrão, sugerindo que há mais cerveja para dividir com os amigos, solucionando assim um problema.

A média dos arquétipos também foi analisada na pesquisa referente à nova campanha da marca, sendo:

Figura 02: Média dos Arquétipos - campanha nova (2017).

\section{Campanha Nova}

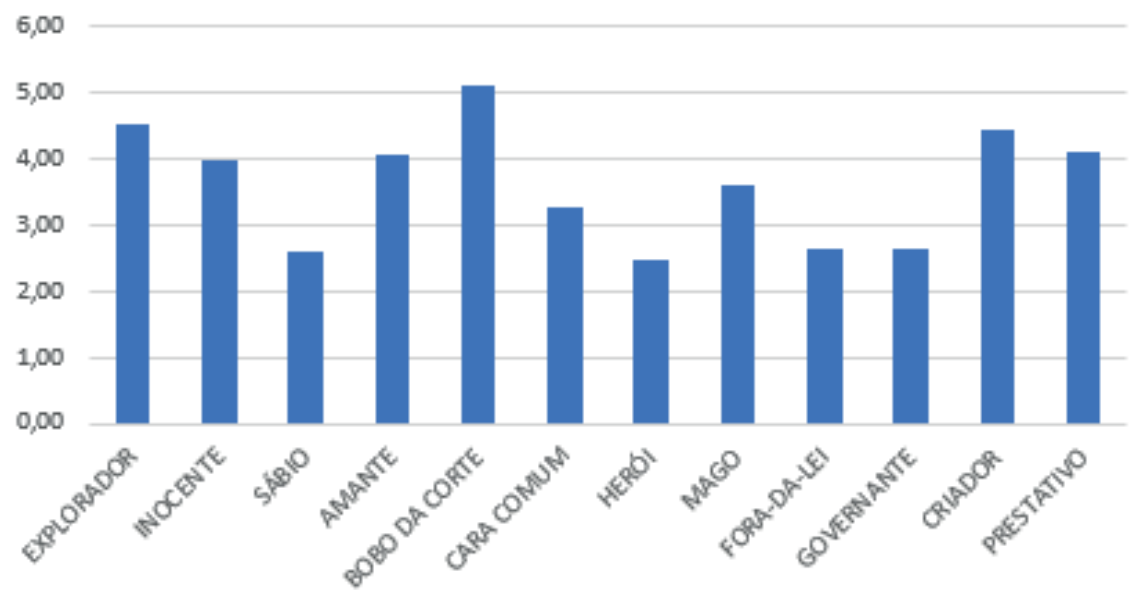

Fonte: elaborado pelos autores.

Diferente do gráfico anterior, nota-se neste segundo momento a presença de mais arquétipos atrelados à percepção da marca Skol, tais como: o Explorador, o Criador e um considerável avanço do arquétipo Prestativo na imagem da marca. Esses arquétipos agregam à Skol ca- 
racterísticas como a busca por liberdade, a descoberta por novas experiências, a inovação, a criatividade, a originalidade, a empatia e a generosidade. Essas qualidades figuram como novos adjetivos que, anteriormente, não eram percebidos pelo consumidor na comunicação da marca. Além desses, o Bobo da Corte se manteve em evidência e é ainda o arquétipo com a presença mais forte, adjetivando a marca como irreverente e espontânea. Também se destaca a redução da percepção do arquétipo do Mago, demonstrando que a marca deixa de aparecer como uma solucionadora de problemas aos consumidores.

Além disso, um terceiro gráfico foi elaborado durante a pesquisa para representar os arquétipos percebidos na imagem da marca por um grupo de controle para compará-lo aos demais. Neste momento da pesquisa, muitos resultados se atrelaram aos demais, segundo a figura 02:

Figura 03: Média dos Arquétipos - imagem da marca.

\section{Imagem da Skol}

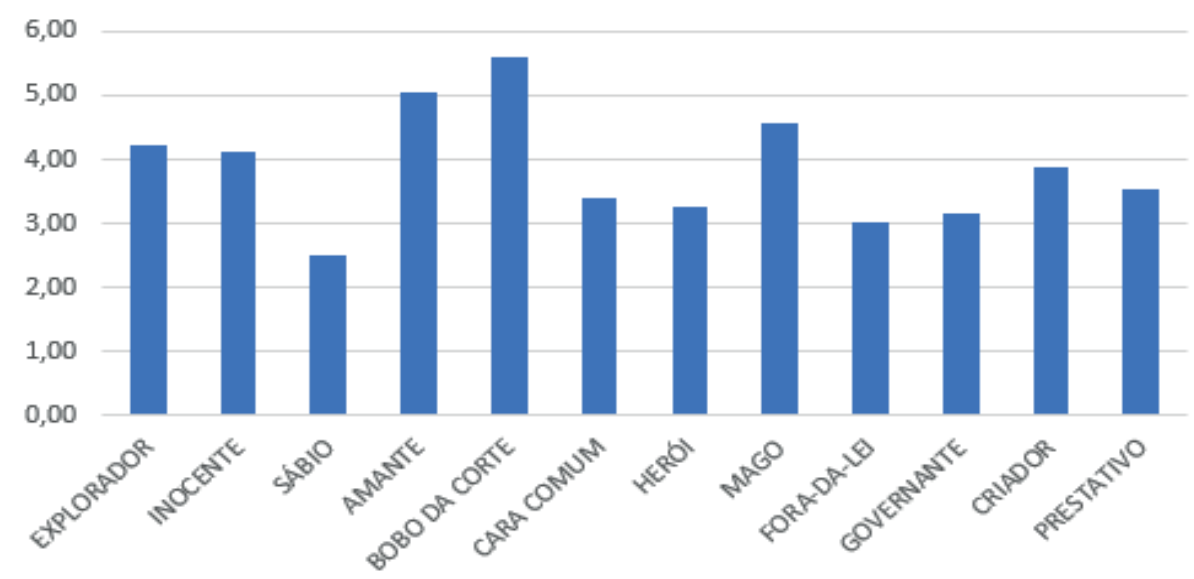

Fonte: elaborado pelos autores.

No terceiro grupo, o de controle, há a presença dos arquétipos do Bobo da Corte e do Mago - assim como no primeiro - e também do arquétipo do Amante, que ganhou grande destaque na lembrança de marca do consumidor. Isto representa um lado mais sensual presente na imagem da marca, de um arquétipo que busca a beleza e os prazeres. 
Uma hipótese para o destaque ao arquétipo do Amante é a forma como a Skol se comunicou durante anos no passado, quando a marca associava seu produto a belas mulheres e de forma visualmente sensualizada. Infere-se, nesse ponto, que essa imagem pode ainda estar presente predominantemente no inconsciente do consumidor. Outro ponto que pode ser percebido comparando os três gráficos é a baixa média do arquétipo do Sábio, o que apresenta a Skol como uma marca que não busca a verdade, a ciência, tampouco o conhecimento, na visão de seus consumidores.

\section{Análise de variância (ANOVA)}

Apesar das médias nos oferecerem a possibilidade de uma análise inicial dos dados mensurados, julgamos necessário realizar uma análise de variância a fim de saber se, estatisticamente, as médias encontradas têm alguma diferença significativa. Para tanto, utilizamos o método ANOVA, no qual os valores das respostas são comparados visando encontrar homogeneidade (ou não) entre os resultados obtidos no corpus. O teste de análise de variância (ANOVA) é indicado para a verificação da diferença das médias mensuradas, assim, o pesquisador descobre se as diferenças encontradas são relevantes, ou se podem ser atribuídas ao acaso (DOANE; SEWARD, 2014, p. 435). Assim, o nível de significância - representado por Sig. - deve ser menor que 0,05. Caso contrário, as diferenças entre as médias não podem ser consideradas relevantes. 0 primeiro teste, apresentado na Tabela 01, representa a análise de variância das médias considerando a comparação dos três grupos (campanha nova, campanha antiga e grupo de controle):

Tabela 01: Teste de análise de variância.

\begin{tabular}{|l|l|l|}
\hline \multicolumn{1}{|c|}{ Arquétipo } & \multicolumn{2}{c|}{ Sig. } \\
\hline Explorador & 0,015 & $<0,05$ \\
\hline Inocente & 0,657 & $>0,05$ \\
\hline Sábio & 0,089 & $>0,05$ \\
\hline
\end{tabular}




\begin{tabular}{|l|l|l|}
\hline Amante & 0,034 & $<0,05$ \\
\hline Bobo da Corte & 0,347 & $>0,05$ \\
\hline Cara Comum & 0,865 & $>0,05$ \\
\hline Herói & 0,116 & $>0,05$ \\
\hline Mago & 0,012 & $<0,05$ \\
\hline Fora-da-Lei & 0,252 & $>0,05$ \\
\hline Governante & 0,379 & $>0,05$ \\
\hline Criador & 0,439 & $>0,05$ \\
\hline Prestativo & 0,002 & $<0,05$ \\
\hline
\end{tabular}

Fonte: elaborado pelos autores.

A Tabela 01 traz os valores obtidos após a aplicação do teste ANOVA, no qual houveram quatro resultados inferiores a 0,05. Isso significa que as percepções médias dos arquétipos do Explorador, do Amante, do Mago e do Prestativo são de diferença estatística significativa nos resultados. Porém, o teste ANOVA não identifica onde se encontra essa diferença significativa. Para tanto, Doane e Seward (2008) indicam a realização de um teste complementar, o Tukey. Este teste servirá para comparar os resultados entre os três tratamentos. E assim, verificar se ocorreu alguma alteração na imagem da Skol em cada situação. Os dados são apresentados nas tabelas seguir:

Tabela 02: Tukey: arquétipo do Explorador.

\begin{tabular}{|c|c|c|c|}
\hline EXPLORADOR & NOVA & ANTIGA & CONTROLE \\
\hline NOVA & - & $\mathbf{0 , 0 1 4}$ & 0,108 \\
\hline ANTIGA & 4,04 & - & 0,745 \\
\hline CONTROLE & 2,884 & 1,036 & - \\
\hline
\end{tabular}

Fonte: elaborado pelos autores.

Para o arquétipo do Explorador, a variância significativa se deu entre as médias das respostas do questionário com a campanha nova e da campanha antiga (Sig. 0,014). A análise desse dado conclui a hipótese de que o consumidor realmente vê a Skol como uma marca com o perfil do Explorador em mais destaque atualmente do que no passado, tornando a imagem da marca mais liberal e aberta a novas experiências. 
Tabela 03: Tukey: arquétipo do Amante.

\begin{tabular}{|c|c|c|c|}
\hline AMANTE & NOVA & ANTIGA & CONTROLE \\
\hline NOVA & - & 0,960 & $\mathbf{0 , 0 4 4}$ \\
\hline ANTIGA & 0,382 & - & 0,081 \\
\hline CONTROLE & 3,439 & 3,068 & - \\
\hline
\end{tabular}

Fonte: elaborado pelos autores.

Na análise Tukey para o arquétipo do Amante, a variância ocorreu entre as médias do grupo de controle, que tinha como estímulo apenas a lembrança de marca, e do grupo que analisou a campanha nova. Nesse caso, houve uma percepção significativamente inferior do arquétipo do Amante para os consumidores que viram a campanha nova. Isso demonstra que na lembrança da marca ainda há a presença de resquícios de uma imagem sexualizada da comunicação da Skol com seu público. Entretanto, num movimento contrário, as campanhas atuais vêm modificando essa percepção.

Tabela 04: Tukey: arquétipo do Bobo da Corte.

\begin{tabular}{|c|c|c|c|}
\hline $\begin{array}{c}\text { BOBO DA } \\
\text { CORTE }\end{array}$ & NOVA & ANTIGA & CONTROLE \\
\hline NOVA & - & 0,417 & 0,999 \\
\hline ANTIGA & 1,790 & - & 0,426 \\
\hline CONTROLE & $\mathbf{0 , 0 3 4}$ & 1,770 & - \\
\hline
\end{tabular}

Fonte: elaborado pelos autores.

Apesar do arquétipo Bobo da Corte não ter apresentado diferença significativa entre as médias dos grupos no teste ANOVA, na análise Tukey ele apresentou variância entre o grupo de controle e o grupo que respondeu às questões sobre a campanha nova. Para o grupo de controle a Skol é vista fortemente como uma marca descontraída e engraçada, enquanto para o outro grupo há uma redução significativa da percepção do arquétipo, ainda que o Bobo da Corte seja o arquétipo mais percebido pelos três grupos. 
Tabela 05: Tukey: arquétipo do Mago.

\begin{tabular}{|c|c|c|c|}
\hline MAGO & NOVA & ANTIGA & CONTROLE \\
\hline NOVA & - & $\mathbf{0 , 0 1 0}$ & 0,639 \\
\hline ANTIGA & 4,187 & - & 0,126 \\
\hline CONTROLE & 1,278 & 2,780 & - \\
\hline
\end{tabular}

Fonte: elaborado pelos autores.

Para o arquétipo do Mago, a diferença se deu entre a campanha nova e a campanha antiga, ocorrendo uma redução significativa da percepção do arquétipo. Há a hipótese de que a própria campanha tenha ocasionado esta percepção, pois o comercial de 2010 traz o arquétipo do Mago na solução dos problemas com a Skol Litrão, diferente da campanha atual.

Tabela 06: Tukey: arquétipo do Governante.

\begin{tabular}{|c|c|c|c|}
\hline GOVERNANTE & NOVA & ANTIGA & CONTROLE \\
\hline NOVA & - & 0,435 & 0,999 \\
\hline ANTIGA & 1,748 & - & 0,471 \\
\hline CONTROLE & $\mathbf{0 , 0 3 3}$ & 1,660 & - \\
\hline
\end{tabular}

Fonte: elaborado pelos autores.

Assim como o arquétipo do Bobo da Corte, o Governante não apresentou diferença significativa entre os grupos pelo teste ANOVA, mas quando analisado pelo método Tukey, ele apresentou uma diferença considerável entre o grupo de controle e da campanha nova. Assim, houve uma redução significativa na percepção do arquétipo pelo grupo que analisou a campanha atual, o que significa, para a marca, uma redução na percepção de poder, controle, segurança, prestígio e solidez.

Tabela 07: Tukey: arquétipo do Prestativo.

\begin{tabular}{|c|c|c|c|}
\hline PRESTATIVO & NOVA & ANTIGA & CONTROLE \\
\hline NOVA & - & $\mathbf{0 , 0 0 2}$ & 0,095 \\
\hline ANTIGA & 4,947 & - & 0,403 \\
\hline CONTROLE & 2,968 & 1,826 & - \\
\hline
\end{tabular}


Fonte: elaborado pelos autores.

De todos os arquétipos, o Prestativo foi o que apresentou maior variância estatística entre os grupos, isto se deu entre a campanha antiga e a campanha nova. Houve um aumento significativamente superior da percepção do arquétipo do Prestativo em sua campanha nova, o que faz da Skol, na visão do consumidor, uma marca mais generosa, empática e com o desejo de mudar o mundo. A hipótese para essa diferença é a de que a própria comunicação da marca tenha adquirido essas características em sua campanha atual, pois o filme publicitário trata da quebra do preconceito sobre casais com idades diferentes, no qual há a diferenciação do comentário definido como "quadrado" - preconceituoso - e do comentário definido como "redondo" - sem preconceitos.

\section{Considerações}

Com o objetivo de identificar quais arquétipos são percebidos na marca Skol pelo público consumidor, a pesquisa se deu por meio de um levantamento teórico seguido de pesquisa experimental. Para isso, foram avaliados dois momentos da comunicação da marca: uma campanha antiga, de 2010, e uma campanha nova, de 2017, além da própria lembrança de marca, sem o estímulo de uma determinada propaganda, servindo como grupo de controle no teste. Os resultados obtidos foram analisados por meio de estatística descritiva e, após, submetidos à análise de variância (ANOVA) e ao teste Tukey para fins de comparação.

$\mathrm{Na}$ análise preliminar, foram identificados nos três momentos o destaque do arquétipo Bobo da Corte, deixando evidente a percepção da Skol como uma marca engraçada e irreverente, mesmo na campanha mais atual, que assume um tom mais responsável na comunicação com seu público. Em contrapartida, o arquétipo do Sábio foi o de menor expressão nos três tratamentos, identificando, assim, a dissociação da Skol como uma marca inteligente. Como foi explanado anteriormente, a imagem de uma marca cria associações e significados na mente do consumidor. Isso explicaria o motivo pelo qual o grupo de controle apresentou respostas similares aos dois grupos que receberam estímulos publicitários, levantando a hipótese de que o grupo de controle - que 
analisou a imagem da marca isoladamente - já possuía uma percepção/ imaginário formado acerca das características predominantes da marca. Dessa forma, é possível concluir que se reconhece em predominância o arquétipo do Bobo da Corte como o de significado mais evidente na memória do consumidor.

Aplicando a análise de variância (ANOVA), foram identificadas as significâncias estatísticas. Como resultado, verificamos que quatro arquétipos - explorador, amante, mago e prestativo - apresentaram valor inferior a 0,05. Mostrando, assim, que as diferenças encontradas nos testes não se configuram como obras do acaso. Dessa forma, a fim de precisar em quais testes se deram essas diferenças, realizou-se o teste Tukey, no qual os tratamentos foram analisados par a par. O teste, por consequência, constatou a diferença de percepção entre a campanha antiga e a campanha nova especialmente no arquétipo do Explorador. Segundo os dados coletados, pode-se inferir que os consumidores percebem a Skol, hoje, como uma marca que estimula a liberdade e a descoberta de novas experiências. Nota-se também a proximidade das respostas do grupo de controle ao grupo que analisou a campanha nova, o que identifica que a imagem da marca começa a tomar a forma da identidade atual na mente do público.

No arquétipo do Amante, o teste acusou diferença estatística entre o grupo de controle e a nova campanha da marca, onde houve uma redução da percepção do arquétipo para o grupo que analisou a campanha nova. Esse resultado levanta a hipótese de que no grupo de controle há uma imagem definida da Skol, resultante das campanhas antigas da marca, quando a publicidade de cerveja ainda se valia do apelo sensual em seus comerciais, o que explica a diferença nos dois tratamentos. Quanto ao arquétipo do Bobo da Corte, o que melhor representou a Skol segundo os consumidores, houve uma redução em sua percepção quando comparados grupo de controle versus campanha nova, o que levanta a hipótese de que a marca busca se comunicar hoje de maneira diferente do passado. Em relação ao grupo de controle, ainda se nota fortemente a presença da identidade antiga da Skol na percepção desse arquétipo. Para o arquétipo do Mago, a diferença se deu entre a campanha antiga e a campanha nova, o que apontou a redução na percepção da marca como a solução para problemas. Como já levantada na análise dos resultados, a hipótese é de que o estímulo publicitário 
(no caso, a campanha antiga) tenha favorecido essa percepção, pois o conteúdo do comercial apresenta o produto como uma solução.

Houve uma redução na percepção do arquétipo do Governante para o grupo que analisou a campanha nova em relação ao grupo de controle, a hipótese levantada é de que a marca é vista hoje de forma mais horizontal, ou seja, mais próxima do seu consumidor do que era antigamente. Esse fato se relaciona com o arquétipo que apresentou maior diferença estatística entre os grupos: o Prestativo $(0,002<0,05)$. Nesse caso, a diferença se deu entre a campanha nova e a campanha antiga, havendo um aumento do arquétipo percebido para o grupo que analisou a nova campanha. Isso dá à Skol a imagem de uma marca empática, generosa e que busca melhorar o mundo.

Ao se defrontar com esses resultados e compará-los aos desejos apresentados pela diretora de marketing da Ambev, Maria Fernanda Albuquerque, em uma entrevista ao portal Propmark em 2017, de que o objetivo era tornar a marca mais próxima e íntima do público, percebe-se que os esforços publicitários de reposicionamento da identidade da Skol estão gerando algum resultado. Isto reforça a importância de se trabaIhar a imagem de uma marca e de como os arquétipos são de grande utilidade para a mensuração de seus significados junto ao público, pois eles retratam, de forma simbólica, a percepção do ponto de vista da recepção.

Ao final, o estudo contribui no destaque à eficiência do uso dos arquétipos pela publicidade, no meio acadêmico e profissional, já que, comprovadamente, eles servem como base para a personificação de uma marca e sua construção frente ao público consumidor. Embora seja de essencial importância pensar nos arquétipos enquanto formas de construir identidades de marca, torna-se cabível, também, sugestionar a melhoria dos resultados e a projeção de novas pesquisas com o mesmo tema, para que se preencham as lacunas desse estudo. Como exemplo, pode-se instigar uma pesquisa comparativa de concorrência com o objetivo de analisar os arquétipos percebidos não apenas na marca Skol, mas também em outras marcas de cerveja, tendo em vista a possibilidade de encontrar semelhanças e diferenças entre a identidades das marcas por meio da teoria dos arquétipos. 


\section{REFERÊNCIAS}

AAKER, David A. Construindo Marcas Fortes. Porto Alegre: ArtMed, 2007.

AAKER, David A. Criando e Administrando Marcas de Sucesso. São Paulo: Editora Futura, 1996.

AAKER. David A. Marcas: Brand Equity: Gerenciando o Valor da Marca. São Paulo: Elsevier, 1998.

AMBEV. Cervejas: Skol. Disponível em: <https://www.ambev.com.br/marcas/cervejas/skol/skol>

CALDAS, Alexandre; GODINHO, Luiz A. C. A percepção quanto ao valor da marca. Belo Horizonte: 2007.

DATAFOLHA. Folha Top of Mind. 26 out. 2016. Disponível em: <http://media.folha.uol.com.br/datafoIha/2016/10/26/top_of_mind_2016.pdfs

DOANE D. P.; SEWARD L. E. Estatística aplicada à Administração e a à Economia. São Paulo: McGraw-Hill, 2008.

DOANE, David P; SEWARD, Lori E. Estatística aplicada à administração e economia. 4 ed. Porto Alegre: Bookman, 2014.

FACEBOOK SKOL. Disponível em: <https://www.facebook.com/skol>

INPI. Marcas: marca, o que é? Disponivel em:

$<$ http://www.inpi.gov.br/servicos/perguntas-frequentes-paginas-internas/perguntas-frequentes-marca\#marca>

JUNG, Carl. G. Os arquétipos e o inconsciente coletivo. Petrópolis: Vozes, 2000.

KAPFERER, Jean-Noël. As marcas, capital da empresa: criar e desenvolver marcas fortes. Porto Alegre: Bookman, 1997.

KELLER, K. L. Conceptualizing, measuring and managing customer-based brand equity. Journal of Marketing. v. 57, n.1, p.1-22, 1993

KHAUAJA, Daniela M. R. Construção de marcas. In: SERRALVO, F. A. (Org.). Gestão de marcas no contexto brasileiro. São Paulo: Saraiva, 2008.

KOTLER, Philip. Administração de marketing: análise, planejamento, implementação e controle. São Paulo: Atlas, 1998.

KOTLER, Philip; KELLER, Kevin L. Administração de Marketing. 14. ed. São Paulo, Pearson Prentice Hall, 2012.

LINDSTROM, Martin. Brand Sense: segredos sensoriais por trás das coisas que compramos. Tradução: Renan Santos - Porto Alegre: Bookman, 2012.

MACIEL, Corintha. Mitodrama: O Universo Mítico e seu Poder de Cura. São Paulo: Agora, 2000. MARK, Margaret; PEARSON, Carol S. O Herói e o Fora-da-Lei: como construir marcas extraordinárias usando o poder dos arquétipos. São Paulo: Cultrix, 2001.

MEIO E MENSAGEM. Skol: a marca que cresce redondo. Disponível em: <http://marcas.meioemensagem.com.br/skol-a-marca-que-cresce-redondo> 
MUNDO DAS MARCAS. História da Skol. Disponível em: <http://mundodasmarcas.blogspot.com. br/2006/05/skol-cerveja-que-desce-redondo.html>

PINHO, J. B. O poder das marcas. 3. ed. São Paulo: Summus, 1996.

PROPMARK. Anunciantes: é no desafio que se encontra a chance de fazer diferente. Disponível em: <http://propmark.com.br/anunciantes/e-no-desafio-que-se-encontra-a-chance-de-fazer-diferente>

SANTOS, A. C.; GUIMARÃES, A. E. O Poder da Marca. III ENCONTRO CIENTíFICO E SIMPÓSIO DE EDUCAÇÃO UNISALESIANO, 3, Anais... São Paulo, p. 1-10, 2011.

SCHULTZ, Don E.; BARNES, Beth E. Campanhas estratégicas de comunicação de marca. Rio de Janeiro: Qualitymark, 2001.

SOLOMON, Michael. O Comportamento do Consumidor: comprando, possuindo e sendo. $5^{\text {a }}$. Edição. Porto Alegre: Bookman, 2002.

TELLES, Renato. Posicionamento e reposicionamento de marca: uma perspectiva estratégica e operacional dos desafios e riscos. 2004. 240 f. Tese (Doutorado em Administração) Faculdade de Economia, Administração e Contabilidade, Universidade de São Paulo, São Paulo. 2004

TORQUATO, Gaudêncio. Cultura, Poder, Comunicação e Imagem: Fundamentos da Nova Empresa. São Paulo: Pioneira, 1991.

WHEELER, A. Design de Identidade da Marca. 3. ed. Porto Alegre: Bookman, 2012.

YOUTUBE SKOL. Disponível em: <https://www.youtube.com/user/skolweb>

Data de Recebimento:10 setembro 2019

Data de Aprovação: 20 março 2020 


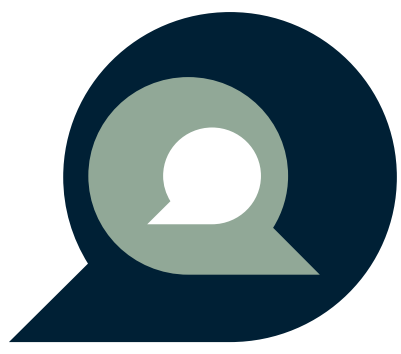

